\title{
PREVALENCE OF MUSCULOSKELETAL INJURIES AMONG YOUNG SQUASH PLAYERS IN MALAYSIA
}

\author{
M. Sankaravel", A. C. Lee, S. Mondam, and J. F. L. Low \\ Faculty of Sports Science and Coaching, Universiti Pendidikan Sultan Idris, Tg Malim, Perak, \\ Malaysia
}

Published online: 10 November 2017

\begin{abstract}
The aim of the study was to investigate the prevalence of musculoskeletal injuries sustained by young squash players in Malaysia. This study was conducted retrospectively by using Standardized Nordic Questionnaire (NSQ) during SUKMA 2016 at Kuching, Sarawak, Malaysia. The questionnaires were distributed to the squash players after getting the approval from the authorities. Totally 94 questionnaires were distributed and 60 questionnaires $(62.5 \%)$ were returned with completed answers. The mean age of the respondents were $17.58 \pm 3.042$ years with $8.85 \pm 3.013$ years of experience of playing squash. Among the respondents $83.33 \%$ were reported that they had musculoskeletal problems during last 12 months. The wrist and hand were the area with the highest (31.7\%) prevalence of musculoskeletal symptoms, and the elbow with least $(8.3 \%)$ prevalence among the respondents.
\end{abstract}

Key Words: Squash, musculoskeletal, injury, survey, evaluation

Author Correspondence, e-mail: mohan@fsskj.upsi.edu.my

doi: http://dx.doi.org/10.4314/jfas.v9i6s.83 


\section{INTRODUCTION}

Squash is one of the popular competitive sports played in Malaysia. It is a high-intensity, intermittent sport, which requires quick movements as maintaining control over placement of the ball with greatest spatial awareness. Since this game encumbers a high level of fitness from the players, who are usually active for the majority of the playing time [1]. As Malaysia is one among 155 squash playing countries, it's having good track records in the world ranking of its players and always thriving to keep its ranking positions throughout the year. Consequently, the ongoing increase in popularity of squash among Malaysians has been associated with an increase in competitive levels in school leagues, at state level and at national level. At the national level, the SUKMA games in Malaysia held once every two years for Malaysian youth players. This event is often viewed as a high end national level competition and is usually referred to as the "Malaysian Olympics" for young adolescent players. Squash is one of the core sporting events in SUKMA.

Young squash players are now participating at relatively more competitive levels of play compared with 20 years ago. According to Eime, Zazryn and Finch (2003), the shift in focus among young people from enjoyment of physical activity to competitiveness is placing high demands on the musculoskeletal and physical systems [2]. The involvement in sporting activities sometime may produce inevitable and unpredictable injuries although caution is taken on safe sporting environment set-ups and good fitness levels of athletes [3]. The incidence of injury varies widely within and between sports; and age groups as well. Squash is also not compromised anywhere for this and even the adolescent or youngsquash players. According to Bylak and Hutchinson, (1998) the maturing adolescent musculoskeletal system may increasethe risk of musculoskeletal injury [4]. The biomechanical demands placed on the vulnerable neuro-musculoskeletal system of young people by high-intensity sports such as squash may be an injury risk factor [5]. Thus, the incidences of musculoskeletal injuries among such players are thought to be at higher rate. However, the informations regarding the injury rate and injury type among Malaysian squash players especially young players are still lacking. Hence, this study was aimed to conduct to investigate the rate of injuries and type of injuries among Malaysian young squash players. 


\section{METHODS}

\subsection{Participants}

This study was conducted during the SUKMA 2016 at the Squash complex, Kuching, Sarawak. The Standardized Nordic Questionnaire (SNQ) questionnaires were distributed to the young squash players after getting permission from the chair of the technical committee for Squash in SUKMA 2016 and from the respective state coaches. Consents were obtained from the respective state coaches and the players before administrating the data collection procedures from the young athletes. For the purpose of the study the young athletes were defined as the athletes within the age of 13-21 years from various states of Malaysia and representing their respective states for the event squash in SUKMA 2016 were called as young squash players. An injury was defined as any pain and or disability sustained by the squash player during competitions or training sessions resulting in time lost from sports participation in last 12 months.

\subsection{Instrument}

A retrospective study of all musculoskeletal injuries occurring to young squash players were undertaken by using SNQ [6]. The questionnaire consists of 2 parts and a diagram showing clearly of 9 anatomical sites to assist the players for the assessment of musculoskeletal symptoms. First part was on the demographic data and the second part were on the musculoskeletal symptoms and related anatomical sites.

\subsection{Procedure}

The questionnaires were distributed to the players after explaining the purpose and importance of the study. Since this study was purely voluntary, the players were permitted to withdraw from the study by returning questionnaire without responding the questions. This study was supported by the University Research Grant. The questionnaires were distributed by the researcher with the help of field-assistants to the players a day before to the tournament. The players were asked to answer any injury incidence during last 12 months of time. All sort of assistance were provided by the researchers to answer the questions in the questionnaire. The players were given two days time to return their questionnaires. The collected data was analyzed by using Statistical Package of Social Science (SPSS) version 23.0 for windows. Microsoft Excel 2010 was also used to key in the collected data. Descriptive statistical 
analysis was conducted to describe the characteristics of studied variables as mean, standard deviation and frequency.

\section{RESULTS AND DISCUSSION}

\subsection{Demography}

A total of $60(62.5 \%)$ players were responded the questionnaire from 96 players. Table 1 shows the demographic details of the respondents.

Table 1. Demography of the respondents

\begin{tabular}{lcc}
\hline Characteristics & Frequency (\%) & Mean \pm SD \\
\hline Age (year) & & $17.58 \pm 3.042$ \\
\hline Gender & $29(48.33 \%)$ & \\
Boys & $31(51.67 \%)$ & \\
Girls & \\
\hline Experience in Playing Squash(year) & \\
\hline \\
\multicolumn{2}{c}{$\mathrm{N}=60$}
\end{tabular}

The mean age of the respondents was $17.58 \pm 3.042$ years. The respondents were $51.67 \%$ girls and $48.33 \%$ boys. The mean experience in playing squash was $8.85 \pm 3.013$ years.

Table 2. Prevalence of Musculoskeletal symptoms during the last 12 moths

\begin{tabular}{lll}
\hline $\begin{array}{l}\text { Musculoskeletal } \\
\text { Symptoms }\end{array}$ & Frequency & Percentage (\%) \\
\hline Yes & 50 & $83.33 \%$ \\
No & 10 & $16.67 \%$ \\
\hline & &
\end{tabular}

A total of $83.33 \%$ respondents were had an experience of having musculoskeletal problems in any one of the nine defined anatomical site in the SNQ during the last 12 months of period (Table 2).

The following Table 3 and Figure 1 shows and compares that the wrist and hand were the area with the highest $(31.7 \%)$ prevalence of musculoskeletal symptoms, followed by ankle/feet (26.7\%), shoulder (25\%) hip/thigh and Knee were equal of (20\%), Neck and Upper back were 
also equal (16.7\%), Lower back was the second least (11.7\%) and the elbow with least $(8.3 \%)$ prevalence among the respondents.

Table 3. Prevalence of Musculoskeletal symptoms by anatomical site

\begin{tabular}{lll}
\hline Anatomical Site & Frequency & Percentage \\
\hline Neck & 10 & 16.7 \\
Shoulder & 15 & 25 \\
Elbow & 5 & 8.3 \\
Wrist/Hand & 19 & 31.7 \\
Upper back & 10 & 16.7 \\
Lower back & 7 & 11.7 \\
Hip/Thigh & 12 & 20 \\
Knee & 12 & 20 \\
Ankle/Feet & 16 & 26.7 \\
& &
\end{tabular}

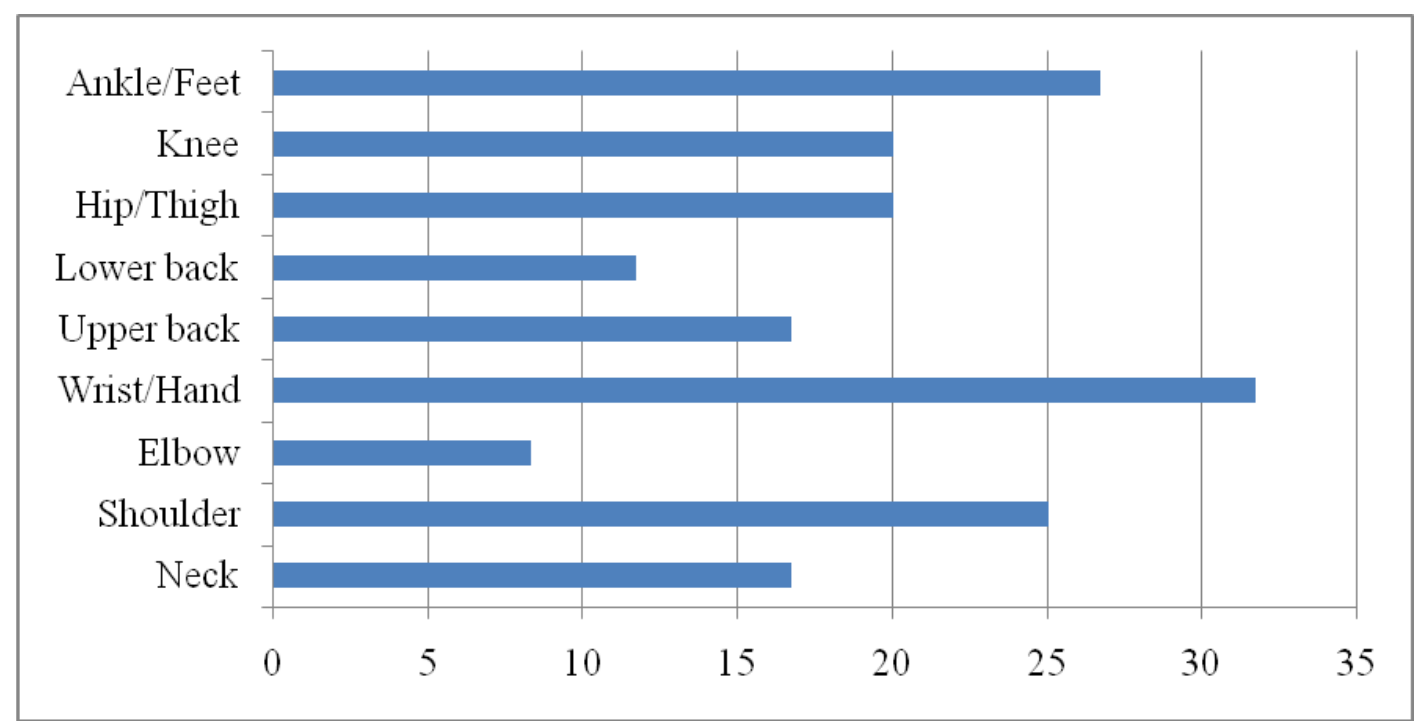

Fig.1. Comparison of musculoskeletal symptoms by anatomical site

The high level young squash players representing to their states for a national level competition like SUKMA, tended to play more frequently, more hastily became more involved in the game, and played for a longer time than the other players. Hence, the authors believe the samples selected were representative of the overall young squash players' population in general and we can therefore meaningfully predict the prevalence of injuries among young squash players.

The majority squash injuries occur to the lower limb $32 \%$ to $58 \%$ of all injuries [1], and the 
authors also stated in their review that ankle was found to be the most frequent injury site contributing to $13 \%$ to $16 \%$ of all squash injuries and followed by the knee accounted for $7 \%$ to $9 \%$. Figure 1 summarizes the commonly injured anatomical site in young squash players and current study shows about $26.7 \%$ of the young athletes were suffered from the ankle injuries, $20 \%$ of the players were injured their knee and $20 \%$ of the players were reported on musculoskeletal symptoms at their hip and thigh as well. Unexpectedly, the incidences are higher in this study; however we have surveyed only on the young squash players whereas the previous authors conducted the study on different age groups as well.

According to Finch \& Eime (2001), the upper-limb injuries make up $17 \%$ to $35 \%$ of all squash injuries [1]. From these the elbow was the most commonly injured body region, accounting for approximately $7 \%$ of all squash injuries, most of which are overuse injuries [7]. In contrast to this, a study [8] has reported that the shoulder as the most frequently injured upper-limb region (13\%) of all squash injuries. Injuries to the wrist and hand account for approximately $6 \%$ to $7 \%$ of squash injuries [7]. Surprisingly current study showed wrist and hand injuries (31.7\%) were the highest prevalent injuries than elbow (8.3\%) injuries and shoulder injuries $(25 \%)$ reported by the previous authors. This is possibly because of high level players with long total time spent training and playing. Nevertheless, the total time spent in training and playing squash was not measured in this study, but years of experience playing squash was measured $(8.85 \pm 3.013$ years $)$, which means almost every young $(17.58 \pm 3.042$ years) squash player was started to play squash approximately from the age of six to ten. Moreover, these higher rates of incidence of wrist injuries mounting up an issue regarding whether the young squash players are using the correct racquet and other gears or not. Need to really unearth the answer for this predicament.

In addition to these injuries, neck injuries (16.7\%), upper back injuries (16.7\%) and Lower back injuries (11.7\%) were also reported by the players. Lower back injuries have been reported to account for $10 \%$ to $16 \%$ of squash injuries [7] and [8]. Current study also reported with the same rate of injuries as reported by the previous studies. These types of injuries are because of overuse of the lower back and chronic in nature [9].

This study was conducted retrospectively and $62.5 \%$ players were responded. This kind of epidemiological study was also conducted by various authors in various time periods with 
different set-ups [8], [10] and [11]; however, the response rates from previous studies were reported low or not stated by the researchers. In all these studies, the players were asked to recall their previous injuries over an undefined recall period, thus brought up with the possibility of significant recall bias. As a consequence the current study was designed to survey the musculoskeletal injuries for last 12 months period. Though this study was designed to survey the musculoskeletal injuries in last 12 months period only, it also has the possibility of recall bias.

Despite of this methodological limitation, this current study have demonstrated that $83.33 \%$ of musculoskeletal injuries occurred in the younger squash players ( $<21$ years). This is almost double of the injuries that have been reported by Berson, Rolnick, and Ramos [8]. This rapid increment of the prevalence of the injury is may be because now young squash players are participating at relatively more competitive levels of play compared with last 20 years. This shift in focus among young people from enjoyment of physical activity to competitiveness is placing high demands on the musculoskeletal and physical systems [3] and the current study is clearly evidencing the need of higher demands on musculoskeletal system.

\section{CONCLUSION}

Though this study was limited to young squash players and their musculoskeletal injuries, this study will definitely be a point of reference for Malaysian young squash players and their injury prevalence. In addition to that, the multiple injuries and recurrent injuries were not inquired. According to the results of this study, there was a very minimal of margin about the prevalence of injury among boys and girls were perceived. The wrist and hand injuries were more common injuries and followed by the other injuries. Thus, authors are recommending the researchers to recognize the risk factors for the wrist and hand injuries especially for the Malaysian young squash players. Though the respondent rate is relatively obsequious, the authors are recommending the authorities to maintain injury report register to serve the players in a better means by planning and executing appropriate prevention and management strategies. 


\section{ACKNOWLEDGEMENTS}

The authors would like to thank the Universiti Pendidikan Sultan Idris for providing opportunity to conduct the study under University Research Grant; Authorities from the Persatuan Squash Malaysia, Technical Committee SUKMA 2016, Coaches, managers, players and the field assistants for providing assistance, cooperation and support during the entire study.

\section{REFERENCES}

[1] Finch C, and Eime R. The epidemiology of squash injuries. Int J Sports Med., 2001, 2:1-11

[2] Eime R, Zazryn, and Finc C. Epidemiology of squash injuries requiring hospital treatment. Inj Control Saf Promot., 2003, 10:243-5

[3] Anizu M. Psychological predictors of injury among Malaysian football players. Unpublished report. 2006

[4] Bylak J, and Hutchinson M R. Common sports injuries in young tennis players. Sports Med., 1998, 26: 119-32

[5] Kibler W B, and Safran M R. Musculoskeletal injuries in the young tennis player. Clin Sports Med., 2000, 19:784-92

[6] Kuorinka I, Jonsson B, and Kilbom A, Standardized Nordic questionnaires for the analysis of musculoskeletal symptom. Journal of Applied Ergonomic., 1987, 18: 233-237

[7] Chard M, and Lachmann M. Racquet sports-patterns of injury presenting to a sports injury clinic. Br J Sports Med., 1987, 21(4):150-153

[8] Berson B, Rolnick A, Ramos C, and Thornton J. An epidemiologic study of squash injuries. Am J Sports Med., 1981, 9(2):103-106

[9] vanDijk C. N. Injuries in squash. In Renstrom P. A, (Eds.), Clinical Practice of Sports Injury Prevention and Care. London: Blackwell Scientific Pubs, 1994, pp. 486-494.

[10]Macfarlane D J, and Shanks A. Back injuries in competitive squash players' Sports Med Phys Fit., 1998, 38(4):337-343

[11]Eubank C, and Messenger N. The frequency and causes of injury in squash. J Sports Sci., 2000, 18(1):13-14 
How to cite this article:

Sankaravel M, Lee A. C, Mondam S, Low J. F. L. Prevalence of musculoskeletal injuries among young squash players in Malaysia. J. Fundam. Appl. Sci., 2017, 9(6S), 1132-1140. 